\title{
Lachesis Venom
}

National Cancer Institute

\section{Source}

National Cancer Institute. Lachesis Venom. NCI Thesaurus. Code C87563.

A homeopathic remedy derived from the venom of the bushmaster snake, Lachesis

Muta, found in Central and South America. Fresh lachesis is diluted in alcohol to obtain the mother tincture. 